\title{
Anterior Cruciate Ligament Publications in Asia in 10 Years: A Systematic Review
}

\author{
Sholahuddin Rhatomy (iD ${ }^{1,2,{ }^{*}}$, Riky Setyawan ${ }^{3}$, Anggaditya Putra ${ }^{4}$ and Dwikora Novembri Utomo ${ }^{5,6}$ \\ ${ }^{1}$ Department of Orthopaedics and Traumatology, Dr. Soeradji Tirtonegoro General Hospital, Klaten, Indonesia \\ ${ }^{2}$ Faculty of Medicine, Public Health, and Nursing, Universitas Gadjah Mada, Yogyakarta, Indonesia \\ ${ }^{3}$ Soeradji Tirtonegoro Sport Center and Research Unit, Dr. Soeradji Tirtonegoro General Hospital, Klaten, Indonesia \\ ${ }^{4}$ Department of Orthopaedics and Traumatology, Fatmawati General Hospital, Jakarta, Indonesia \\ ${ }^{5}$ Department of Orthopaedics and Traumatology, Dr. Soetomo General Hospital, Surabaya, Indonesia \\ ${ }^{6}$ Faculty of Medicine, Universitas Airlangga, Surabaya, Indonesia \\ Corresponding author: Sport and Adult Reconstructive Division, Orthopaedics and Traumatology Department, Dr. Soeradji Tirtonegoro General Hospital, Street Number 1, \\ Tegalyoso, South Klaten, Klaten, Indonesia. Tel: +62272-321102, Fax: +62272-321104, Email: doktergustomrhatomy@yahoo.com \\ Received 2020 June 07; Revised 2020 August 19; Accepted 2020 September 01.
}

\section{Abstract}

Background: There have been numerous articles about the anterior cruciate ligament (ACL). But there has been no specific article describing ACL in Asian countries.

Objectives: This study aims to provide the publications about ACL in Asian countries in the last 10 years.

Methods: We searched English full text with keywords “ACL" OR "Anterior Cruciate Ligament" AND “injury" OR "tear" OR “rupture” that were published from January 1st 2010 to December 31st 2019 on PubMed, EMBASE, and Cochrane Library. We included articles with at least one author affiliation in an Asian country. We analyzed the number of published articles per year, top 10 journals with the highest number of publications, top 5 authors with the highest number of published articles in the first order author, top 10 countries with the highest number of published articles, and the type of study.

Results: A total of 821 articles were analyzed, of which 821 were included. Analysis of the number of articles by year revealed that 2019 was the highest number of published articles $(n=150 ; 18.3 \%)$. Study type analysis revealed that clinical research $(n=398 ; 48.5 \%)$ was the most frequent study type. Cohort studies were the most frequent type of clinical research $(n=169 ; 42.5 \%)$. The journal of knee surgery, sports traumatology, arthroscopy (KSSTA) had the highest number of publications in general ( $\mathrm{n}=108 ; 13.2 \%)$. Jung Ho $\operatorname{Noh}(n=8)$ was the top author with the highest number of published articles in the first author order, and Ryosuke Kuroda ( $n=24)$ was the top author with the highest number of published articles. Japan was the top country with the highest number of published articles $(n=203 ; 24.7 \%)$. Most of the studies $(n=395 ; 48.1 \%)$ were published in high index journals with an impact factor $>1.0$.

Conclusions: There has been an increase in the ACL publications among Asian authors over the past 10 years with the high impact journal publishers. This article demonstrates the increased interest in the ACL topic and could be used as a basis for future studies.

Keywords: Anterior Cruciate Ligament, Bibliometric, Trends, Impact Factor

\section{Background}

There have been numerous researches about the anterior cruciate ligament (ACL). The ACL is discussed among knee surgeons because it is the most common injured of the knee ligaments (1). Researchers have attempted to provide the evidence in diagnosis, treatment, prevention, prognosis, and rehabilitation techniques in ACL injured patient $(2,3)$. The increase in ACL studies has been caused by the development of ACL reconstruction equipment, cadaver dissection tools, and imaging modalities (4).

The publications trends about this ligament have increased by year around the world. There have been 2 studies about systematic reviews in the ACL scope $(2,5)$, but there still no publication that provides all data about ACL publications, especially in Asian countries. Organizing information in an effective way mandates the use of the best evidence for decision making in ACL care holistically.

Not only in America and Europe, but also in Asia is developing the treatment and diagnosis of ACL injury, and also all about the ACL itself.

\section{Objectives}

This study wants to provide the publication about ACL in Asian countries in the last 10 years. 


\section{Methods}

We searched in PubMed, EMBASE, and Cochrane Library using the keywords "ACL" OR "Anterior Cruciate Ligament” AND "injury" OR "tear" OR "rupture”. We added English full text and 10 years publications in the filter searching engine. The search resulted in a total of 55.702 articles from 2009 until 2019. We included the articles that discussed the anterior cruciate ligament and at least one author with the affiliation country in Asia. All original articles, including molecular study, laboratory study, animal study, cadaveric study, imaging study, clinical study, systematic review, review article, and other studies that were published between January 1st, 2010 until December 31st, 2019, were included. We excluded the book sections, conference presentations, guidelines, commentaries, or personal reviews. The PRISMA guidelines for conducting the review were followed (Figure 1) (6).

All abstracts were screened independently by two reviewers to determine whether it met eligibility criteria. The full articles of eligible studies were reviewed and included in the study for further data extraction and analysis. We analyzed the number of published articles by year, top 10 journals with the highest number of publications, top 10 authors with highest number of published articles in the first order author, top 10 countries with the highest number of published articles, the most cited articles, and type of study. The published journals were divided by impact factor (IF) into low (IF below 1) and high (IF of 1 and above) impact journals. Information of a country was collected. Data was analyzed using Microsoft Excel and SPSS version 25.0 and visualized with tables and graphs

\section{Results}

A total of 821 articles on ACL studies were performed in the Asia region between 2010 until 2019 (Figure 2). The average number of publications is 82 articles per year. The highest number of published articles was in 2019 with 150 articles, and the lowest number of published articles was in 2010 with 24 articles. The trend of ACL publications has a positive incremental value (Figure 2 ). The total number of papers were increased almost every year after the year 2010 and only decreased in 2014.

Knee surgery, sports traumatology, arthroscopy had the highest number of articles $(n=108 ; 13.1 \%)$ followed by the American journal of sports medicine $(n=54 ; 6.6 \%)$ and journal of arthroscopy: the journal of arthroscopic \& related surgery ( $n=53 ; 6.4 \%$ ) (Figure 3 ). The country with the highest number of published articles was Japan ( $n=203$; $24.7 \%)$, followed by China $(\mathrm{n}=173 ; 21.1 \%)$ and South Korea ( $\mathrm{n}=129 ; 15.7 \%$ ) (Figure 4 ). Articles by Kyritsis et al. (7) had the highest number of citations with 212 times (Table 1). The top 10 most cited articles had a number of citations of more than 100 times. Jung Ho Noh from the Department of Orthopaedic Surgery Kangwon National University Hospital, South Korea, was the author with the highest number of published articles in which he was the first order author (Table 2). Authors with the first order authors came from China $(n=2)$, South Korea $(n=1)$, Japan $(n=1)$, and India, respectively $(n=1)$. Ryosuke Kuroda was the author with the highest number of articles with 24 articles (Table 3). The Department of Orthopedic Surgery, Kobe University Graduate School of Medicine, Kobe, Japan, was the most active department that was proven by the highest published article number. Clinical research $(n=410 ; 50.5 \%)$ was the most commonly used type of study in the past 10 years ( $\mathrm{Ta}$ ble 4 ), followed by clinical imaging studies ( $n=96 ; 11.8 \%)$ and surgical technique studies ( $\mathrm{n}=91 ; 11.2 \%)$. Cohort studies were the highest type of clinical research study that constituted $42.6 \%$ of clinical research (Table 5), followed by cross-sectional studies, $25.8 \%$ and case-control studies 13.6\%. In this systematic review, most Asian authors submitted their study in high index journals with impact factors more than $1.0(n=395,48.1 \%)$, and some studies submitted in unindexed journal publishers $(n=47 ; 5.7 \%)$. Most of articles were published in Q1 journals $(n=468 ; 57.0 \%)$, followed by Q2 ( $n=167 ; 20.3 \%), Q 3(n=124 ; 15.1 \%)$, and Q4 ( $n=14 ; 1.7 \%)$.

\begin{tabular}{clc}
\hline Table 1. Top 10 Most Cited Articles & \\
\hline No. & Reference & Number of Citation \\
\hline $\mathbf{1}$ & Kyritsis et al. (7) & 212 \\
$\mathbf{2}$ & Cimino et al. (8) & 196 \\
\hline $\mathbf{3}$ & Yoo et al. (9) & 186 \\
$\mathbf{4}$ & Li et al. (10) & 179 \\
$\mathbf{5}$ & Shin et al. (11) & 170 \\
$\mathbf{6}$ & Gao et al. (12) & 154 \\
\hline $\mathbf{7}$ & Tiamklang et al. (13) & 152 \\
$\mathbf{8}$ & Ahn et al. (14) & 141 \\
\hline $\mathbf{9}$ & Salavati et al. (15) & 122 \\
\hline $\mathbf{1 0}$ & Khayambashi et al. (16) & 121 \\
\hline
\end{tabular}

\section{Discussion}

The most important findings from this systematic review were that most of the Asian authors published their research in high impact factor journals. It proved that Asian authors have good quality of research protocol. It can be motivated by raising the international ranking of the university or educational center. Asian authors have 


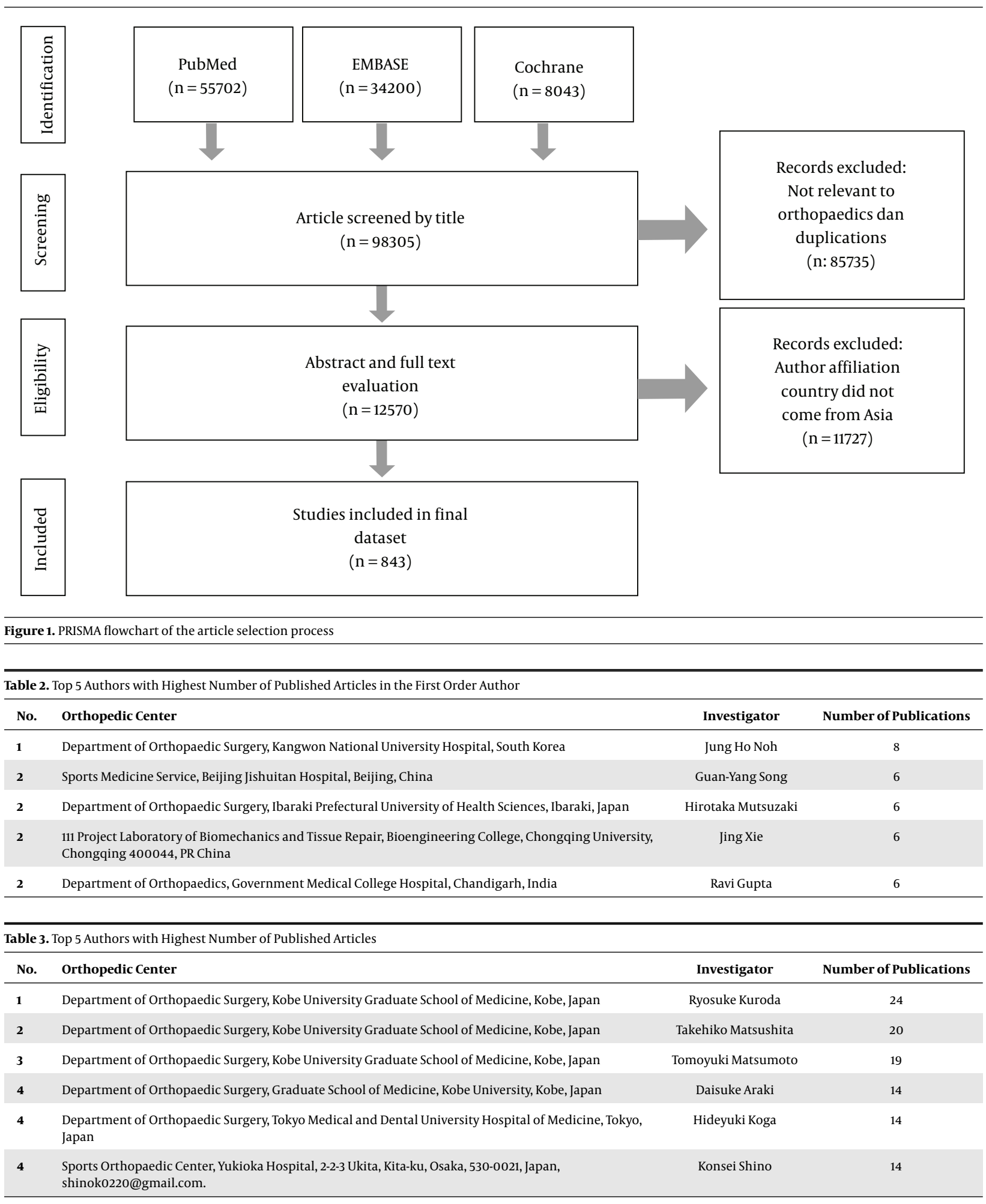

wanted to document and make their work accessible for other surgeons around the world. Most of the articles were published in the Q1 journal (57.0\%) according to the grading by www.scimagojr.com also proved that the quality of 


\begin{tabular}{|c|c|c|c|c|c|c|c|c|c|c|c|c|c|c|}
\hline Year & $\begin{array}{l}\text { Laboratory/ } \\
\text { Molecu- } \\
\text { lar } \\
\text { Study }\end{array}$ & $\begin{array}{l}\text { Animal } \\
\text { Study }\end{array}$ & $\begin{array}{c}\text { Cadaveric } \\
\text { Anatomy/ } \\
\text { Histology } \\
\text { Study }\end{array}$ & $\begin{array}{l}\text { Cadaveric } \\
\text { Biome- } \\
\text { chanics } \\
\text { Study }\end{array}$ & $\begin{array}{c}\text { Cadaveric } \\
\text { Imaging } \\
\text { Study }\end{array}$ & $\begin{array}{c}\text { Cadaveric } \\
\text { Surgical } \\
\text { Tech- } \\
\text { nique }\end{array}$ & $\begin{array}{l}\text { Clinical } \\
\text { Imaging } \\
\text { Study }\end{array}$ & $\begin{array}{l}\text { Surgical } \\
\text { Tech- } \\
\text { nique }\end{array}$ & $\begin{array}{c}\text { Case } \\
\text { Report }\end{array}$ & $\begin{array}{l}\text { Clinical } \\
\text { Research }\end{array}$ & $\begin{array}{c}\text { Meta- } \\
\text { Analysis } \\
\text { \& System- } \\
\text { atic } \\
\text { Review }\end{array}$ & $\begin{array}{l}\text { Review } \\
\text { Article }\end{array}$ & others & Total \\
\hline 2010 & 3 & 2 & 0 & 0 & 0 & o & 1 & 3 & 0 & 11 & 2 & 2 & 0 & 24 \\
\hline 2011 & 2 & 2 & 0 & 0 & 0 & 0 & 5 & 8 & 6 & 22 & 0 & 1 & 3 & 49 \\
\hline 2012 & 6 & 2 & 0 & 2 & 0 & 3 & 7 & 6 & 10 & 24 & 1 & 0 & 3 & 64 \\
\hline 2013 & 3 & 1 & 0 & 0 & 0 & 1 & 10 & 10 & 7 & 35 & 1 & 3 & 0 & 71 \\
\hline 2014 & 4 & 1 & 1 & 1 & 0 & 2 & 6 & 11 & 6 & 19 & 2 & 4 & 1 & 58 \\
\hline 2015 & 7 & 4 & 0 & 1 & 0 & 0 & 9 & 8 & 5 & 44 & 1 & 3 & 0 & 82 \\
\hline 2016 & 4 & 4 & 0 & 0 & 0 & 1 & 15 & 10 & 4 & 51 & 7 & 0 & 5 & 101 \\
\hline 2017 & 6 & 5 & 0 & 0 & 0 & 0 & 9 & 12 & 5 & 53 & 5 & 1 & 4 & 100 \\
\hline 2018 & 4 & 11 & 0 & 0 & 0 & 1 & 9 & 8 & 8 & 66 & 7 & 6 & 2 & 122 \\
\hline 2019 & 6 & 5 & 1 & 3 & 1 & 0 & 24 & 14 & 3 & 73 & 8 & 7 & 5 & 150 \\
\hline 2020 & 1 & 1 & 0 & 1 & 0 & 0 & 1 & 1 & 1 & 12 & 1 & 2 & 1 & 22 \\
\hline Total & 46 & 38 & 2 & 8 & 1 & 8 & 96 & 91 & 55 & 410 & 35 & 29 & 24 & 843 \\
\hline Year & Cas & Series & & s-Sectional & & Case-Control & & Cohort & \multicolumn{6}{|c|}{ Randomized Controlled Clinical Trial } \\
\hline 2010 & & 6 & & 4 & & 0 & & 1 & \multicolumn{6}{|c|}{0} \\
\hline 2011 & & 0 & & 6 & & 3 & & 13 & \multicolumn{6}{|c|}{0} \\
\hline 2012 & & 5 & & 4 & & 4 & & 7 & \multicolumn{6}{|c|}{4} \\
\hline 2013 & & 5 & & 14 & & 4 & & 10 & \multicolumn{6}{|c|}{2} \\
\hline 2014 & & 1 & & 6 & & 2 & & 7 & \multicolumn{6}{|c|}{3} \\
\hline 2015 & & 3 & & 6 & & 5 & & 21 & \multicolumn{6}{|c|}{9} \\
\hline 2016 & & 0 & & 15 & & 7 & & 21 & \multicolumn{6}{|c|}{8} \\
\hline 2017 & & 4 & & 15 & & 7 & & 22 & \multicolumn{6}{|c|}{5} \\
\hline 2018 & & 5 & & 15 & & 12 & & 33 & \multicolumn{6}{|c|}{1} \\
\hline 2019 & & 7 & & 18 & & 10 & & 34 & \multicolumn{6}{|c|}{4} \\
\hline Total & & 37 & & 106 & & 56 & & 175 & \multicolumn{6}{|c|}{36} \\
\hline
\end{tabular}

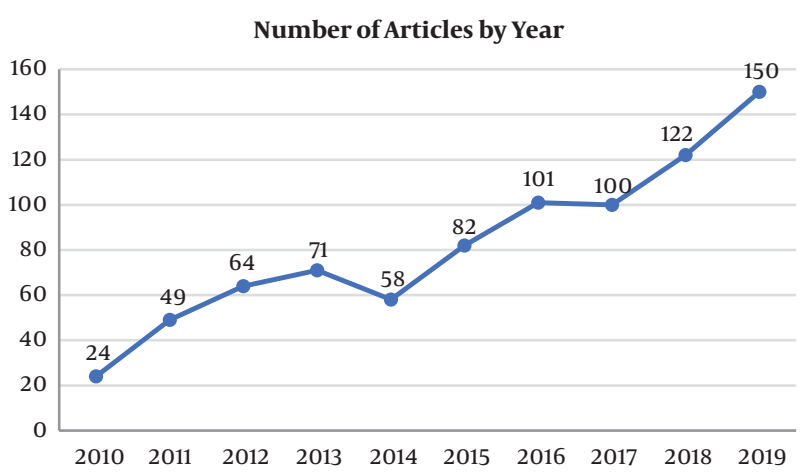

Figure 2. Published articles by year

Asian author research was excellent.

The number of journals increase in the ACL field is associated with the development of new methods in ACL recon- struction. There are still many things to explore in ACL itself, such as in histological features, biomechanics, animal studies, cadaveric studies (4), as well as imaging studies.

Articles with the highest citation number were clinical research with the title: "likelihood of ACL graft rupture: not meeting six clinical discharge criteria before return to sport is associated with a four times greater risk of rupture" with 212 citations. Systematic reviews by Kambhampati and Vaishya showed that: "Knee Injury and Osteoarthritis Outcome Score (KOOS): development of a Selfadministered Outcome Measure" has the highest citation number with 1456 times (2). A study by Vielgut et al. showed that: "rating systems in the evaluation of knee ligament injuries" has the highest citation number with 1624 times (17). Clinical research was dominating in this systematic review. It may be because the background of most Asian authors is an orthopedic surgeon. In this review, there were 297 articles with the number of citations more 


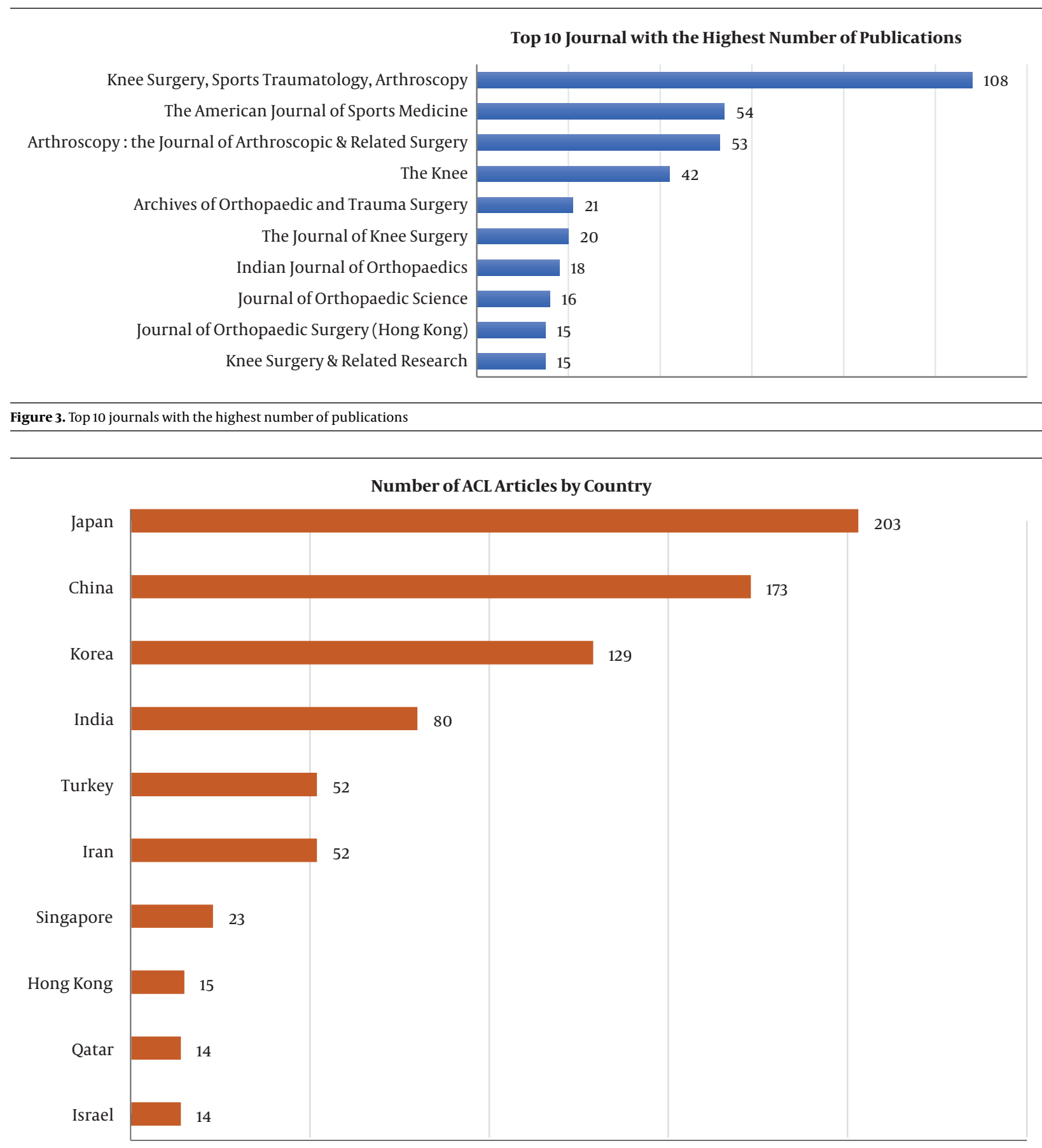

Figure 4. Number of ACL articles by country

than 10 times. It indicates the novelty of the study. Thus the other researcher cited the article.

Japan was the country with the highest number of published articles. It indicates that the development of technology, awareness to update the new and more effective methods of diagnosis, treatment, and rehabilitation programs of the researcher were good. The countries with a small number of published articles did not indicate that they did not have a research protocol. It signifies that whether they had published the article in an unindexed 
journal publisher or they had data to write a manuscript, but they did not have time to write because of the high load of patients to be operated. A study by Kambhampati and Vaishya showed that the United States is the biggest country with the highest number of ACL publications, with 10356 articles (2).

This study indicates the need for collaboration in research in the region. In order to bridge the ACL research gap among Asian countries, international collaborations with guidance from more established research centers should be encouraged. The study by $\mathrm{Wu}$ et al. revealed that the collaboration between low-income countries and middle-income countries has a higher level of evidence and a more prospective controlled design of study (18).

The limitations of his systematic review are that it only focuses on studies performed in the Asia region. Many researchers in Asian countries may have contributed data to an overseas-based research project or participated in research when they resided overseas. This exclusion is to depict a clearer picture of local research output and quality.

\subsection{Conclusions}

There has been an increase in the ACL publications among Asian authors over the past 10 years with high impact journal publishers. This article demonstrates the increased interest in the ACL topic and could be used as a basis for future study.

\section{Footnotes}

Authors' Contribution: Sholahuddin Rhatomy, Riky Setyawan, and Aggaditya Putra conceived the study, collected the data, analysed data. Sholahuddin Rhatomy, Riky Setyawan, and Dwikora Novembri Utomo prepared and drafted the manuscript. Sholahuddin Rhatomy, Aggaditya Putra, and Dwikora Novembri Utomo edited manuscript. Riky Setyawan visualized the data into table and graph. Sholahuddin Rhatomy, Riky Setyawan, and Dwikora Novembri Utomo reviewed and revised the manuscript.

Conflict of Interests: No potential conflict of interest relevant to this article was reported.

Funding/Support: The authors declare that this study had no funding resource.

\section{References}

1. Davies GJ, McCarty E, Provencher M, Manske RC. ACL Return to Sport Guidelines and Criteria. Curr Rev Musculoskelet Med.2017;10(3):307-14. doi: 10.1007/s12178-017-9420-9. [PubMed: 28702921]. [PubMed Central: PMC5577421].
2. Kambhampati SBS, Vaishya R. Trends in Publications on the Anterior Cruciate Ligament Over the Past 40 Years on PubMed. Orthop J Sports Med. 2019;7(7):2325967119856880. doi: 10.1177/2325967119856883. [PubMed: 31384616]. [PubMed Central: PMC6647219].

3. Paterno MV. Incidence and Predictors of Second Anterior Cruciate Ligament Injury After Primary Reconstruction and Return to Sport. JAthl Train. 2015;50(10):1097-9. doi: 10.4085/1062-6050-50.10.07. [PubMed: 26509777]. [PubMed Central: PMC4641548].

4. Amano K, Li Q, Ma CB. Functional knee assessment with advanced imaging. Curr Rev Musculoskelet Med. 2016;9(2):123-9. doi: 10.1007/s12178-016-9340-0. [PubMed: 27052009]. [PubMed Central: PMC4896883].

5. Anderson MJ, Browning W3, Urband CE, Kluczynski MA, Bisson LJ. A Systematic Summary of Systematic Reviews on the Topic of the Anterior Cruciate Ligament. Orthop J Sports Med. 2016;4(3):2325967116634070. doi: 10.1177/2325967116634074. [PubMed: 27047983]. [PubMed Central: PMC4794976].

6. Liberati A, Altman DG, Tetzlaff J, Mulrow C, Gotzsche PC, Ioannidis JP, et al. The PRISMA statement for reporting systematic reviews and meta-analyses of studies that evaluate health care interventions: explanation and elaboration. PLoS Med. 2009;6(7). e1000100. doi: 10.1371/journal.pmed.1000100. [PubMed: 19621070]. [PubMed Central: PMC2707010].

7. Kyritsis P, Bahr R, Landreau P, Miladi R, Witvrouw E. Likelihood of ACL graft rupture: not meeting six clinical discharge criteria before return to sport is associated with a four times greater risk of rupture. Br J Sports Med. 2016;50(15):946-51. doi: 10.1136/bjsports-2015-095908. [PubMed: 27215935].

8. Cimino F, Volk BS, Setter D. Anterior cruciate ligament injury: diagnosis, management, and prevention. Am Fam Physician. 2010;82(8):91722. [PubMed: 20949884].

9. Yoo JH, Lim BO, Ha M, Lee SW, Oh SJ, Lee YS, et al. A meta-analysis of the effect of neuromuscular training on the prevention of the anterior cruciate ligament injury in female athletes. Knee Surg Sports Traumatol Arthrosc. 2010;18(6):824-30. doi:10.1007/s00167-009-0901-2. [PubMed 19760399].

10. Li X, Kuo D, Theologis A, Carballido-Gamio J, Stehling C, Link TM, et al. Cartilage in anterior cruciate ligament-reconstructed knees: MR imaging T1\{rho\} and T2-initial experience with 1-year follow-up. Radiology. 2011;258(2):505-14. doi: 10.1148/radiol.10101006. [PubMed: 21177392]. [PubMed Central: PMC3029884].

11. Shin CS, Chaudhari AM, Andriacchi TP. Valgus plus internal rotation moments increase anterior cruciate ligament strain more than either alone. Med Sci Sports Exerc. 2011;43(8):1484-91. doi: 10.1249/MSS.ob013e31820f8395. [PubMed: 21266934].

12. Gao K, Chen S, Wang L, Zhang W, Kang Y, Dong Q, et al. Anterior cruciate ligament reconstruction with LARS artificial ligament: a multicenter study with 3- to 5-year follow-up. Arthroscopy. 2010;26(4):515-23. doi: 10.1016/j.arthro.2010.02.001. [PubMed: 20362832].

13. Tiamklang T, Sumanont S, Foocharoen T, Laopaiboon M. Doublebundle versus single-bundle reconstruction for anterior cruciate ligament rupture in adults. Cochrane Database Syst Rev. 2012;11. CD008413. doi: 10.1002/14651858.CD008413.pub2. [PubMed: 23152258]. [PubMed Central: PMC6464733].

14. Ahn JH, Bae TS, Kang KS, Kang SY, Lee SH. Longitudinal tear of the medial meniscus posterior horn in the anterior cruciate ligamentdeficient knee significantly influences anterior stability. Am J Sports Med. 2011;39(10):2187-93. doi: 10.1177/0363546511416597. [PubMed: 21828365].

15. Salavati M, Akhbari B, Mohammadi F, Mazaheri M, Khorrami M Knee injury and Osteoarthritis Outcome Score (KOOS); reliability and validity in competitive athletes after anterior cruciate ligament reconstruction. Osteoarthritis Cartilage. 2011;19(4):406-10. doi: 10.1016/j.joca.2011.01.010. [PubMed: 21255667]. 
16. Khayambashi K, Ghoddosi N, Straub RK, Powers CM. Hip Muscle Strength Predicts Noncontact Anterior Cruciate Ligament Injury in Male and Female Athletes: A Prospective Study. Am J Sports Med 2016;44(2):355-61. doi:10.1177/0363546515616237. [PubMed: 26646514].

17. Vielgut I, Dauwe J, Leithner A, Holzer LA. The fifty highest cited papers in anterior cruciate ligament injury. Int Orthop. 2017;41(7):1405-12. doi: 10.1007/s00264-017-3513-3. [PubMed: 28550427].

18. Wu HH, Liu M, Patel KR, Turner W, Baltus L, Caldwell AM, et al. Impact of academic collaboration and quality of clinical orthopaedic research conducted in low- and middle-income countries. SICOT J. 2017;3:6. doi: 10.1051/sicotj/2016042. [PubMed: 28134090]. [PubMed Central: PMC5278648]. 